\title{
LAWTE turns 21!
}

The Laboratory Animal Welfare Training Exchange (LAWTE) was born in 1994. That means that today, in 2015, LAWTE has made it to the milestone age of 21 . According to its mission statement, LAWTE is "a global organization that is expanding animal welfare and enhancing public understanding through effective training and education of animal research professionals" (http://www.lawte. org/about). LAWTE has grown up to encompass trainers-both from and for the field of laboratory animal science.

I am an active member of LAWTE; I joined in 1998 and was president in 20122013. Now I wish to recognize the achievements of our organization. The metaphor of growth and maturation is apt for LAWTE because it has been nurtured by its parents, a group composed entirely of volunteers who have collectively devoted so many hours to raising this child. Over the past 21 years, LAWTE has come of age with other training organizations in the family of the lab animal community (Table 1). LAWTE developed many programs in its adolescence, as it became aware of its capabilities. Now in adulthood, it is an established and recognized organization within the lab animal community.

LAWTE was conceived in 1993 as the brain child of Marilyn Miller Heath, Sally Tyree and Michelle Calkins ${ }^{1,2}$. It was then born in 1994, with its first conference in North Carolina. Subsequently there have been birthday party conferences every two years. During early childhood and the school years, the first LAWTE conferences focused on the basics of training. LAWTE learned to communicate during the late 1990s, when Dr. Nicole Duffee developed the LAWTE website (www.lawte.org) and a listserv, which, after a growth spurt, now serves 800 of LAWTE's parents and aunts and uncles. Both the website and the listserv are maintained by LAWTE's cousin, the American Association for Laboratory Animal Science.
In 1997 LAWTE received an official birth certificate when it was incorporated in Michigan as a 501(c)3 (non-profit) organization $^{1}$. In 2002 LAWTE got a real job when I published a description for the generic position of "training coordinator"3. At the age of 13, in 2007, LAWTE learned to share and gave away the first Founder's Award to recognize an outstanding trainer in the field of lab animal science. Three additional awards, named the Impact, Rookie and LAWTE Top 3, were added in 2015.

In 2012 LAWTE renewed its license by updating its constitution and by-laws. The next year, in 2013, LAWTE took its first trip abroad, joining with the Canadian Association of Laboratory Animal Science to hold a joint meeting in Winnipeg, Manitoba. Actually, there has always been an international influence in LAWTE's upbringing, because its relatives include members in and visiting speakers from a dozen different countries. In 2013 and 2015 LAWTE visited with another relative and a peer in training, the Association of Veterinary Technician Educators. This past summer, LAWTE invited the IACUC best practices group to its most recent birthday party conference in Madison, WI.

So what does adulthood portend for LAWTE? It is tough to speculate too far ahead, but for now let me consider just the next decade. Training positions are already

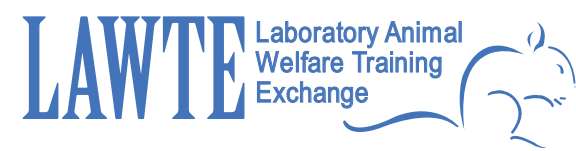

well established in facilities, which help to meet the training obligations prescribed by many regulations and authorities in this field. I expect the number of positions to grow further and I anticipate that a certificate program will be developed. More of us will return to school to enhance our knowledge and skills as teachers and trainers, earning master's and doctorate degrees in education. LAWTE will officially register the term 'CTPer' for Commercial Training Partner to designate vendors who conduct training. I see the word "rubric" entering everyone's vocabulary as we enhance the evaluation and assessment of training. Finally, being a millennial, LAWTE will be into educational technology.

Like an opa or abuelo, I am proud to share in celebrating the organization's 21 st birthday and pleased to honor LAWTE with this column. Cheers!

1. Pritt, S. \& Aranda, G. The history and future of the Laboratory Animal Welfare Training Exchange (LAWTE). ALN Magazine (March 2007).

2. Pritt, S. \& Clifford, P. Happy 20th Birthday to the Laboratory Animal Welfare Training Exchange (LAWTE)! ALN Magazine (December 2014).

3. Kennedy, B.W. Creating a training coordinator position. Lab Anim. (NY) 31, 34-38 (2002).

\begin{tabular}{|c|c|}
\hline Founded (date) & Organization \\
\hline 1949 & Institute of Animal Technology (IAT) \\
\hline 1950 & American Association for Laboratory Animal Science (AALAS) \\
\hline 1957 & American College of Laboratory Animal Medicine (ACLAM) \\
\hline 1961 & Canadian Association of Laboratory Animal Science (CALAS) \\
\hline 1973 & Association of Veterinary Technician Educators (AVTE) \\
\hline 1973 & Public Responsibility in Medicine and Research (PRIM\&R) \\
\hline 1978 & Federation of European Laboratory Animal Science Associations (FELASA) \\
\hline 1984 & Laboratory Animal Management Association (LAMA) \\
\hline 1991 & A Norwegian Inventory of Alternatives (NORINA) \\
\hline 2000 & Collaborative Institutional Training Initiative (CITI) \\
\hline 2015 & Education and Training Platform for Laboratory Animal Science (ETPLAS) \\
\hline
\end{tabular}

